\title{
An analytical exploration and mathematical modeling on the dynamics of sea wave energy conversion to electricity production
}

\author{
Ahmed S. Hassan, and Mohammed Y. Tharwan, Yahya A. Rothan \\ Department of Mechanical Engineering, College of Engineering, \\ Jazan University, P. O. Box 706, Jazan 45142, Kingdom of Saudi Arabia \\ E-mail address: ashassan@jazanu.edu.sa, mtharwan@jazanu.edu.sa, yrothan@jazanu.edu.sa
}

\begin{abstract}
Recently, most countries suffering from global warming due to the waste gases coming out of the combustion engines used to generate electric power by traditional methods. Therefore, many countries are currently trying to find alternative solutions to this problem by using renewable energies such as solar energy, wind energy, and energy generated from the waves of the ocean and sea to overcome pollution problems. The waves of the seas and oceans have enormous and largely untapped energy, so this work presents an efficient way to use the energy of sea waves to generate electricity. And also, trying to be a way to produce electricity from wave energy in the future. The best suitable places along the shores of Jizan city were inspected to install the buoy system to revenue advantage of the wave supreme height to achieve the height amount of electrical energy. A mathematical model was made to analyze the wave energy and convert it into energy extracted by mechanical force. The mathematical analyzes used the data collected from satellite maps of the numerous severe waves in the Red sea of the Jazan area, and the data published in previous research along that area. It was found that the beach of the Al Shuqaiq area is the greatest for installing the buoy and obtaining the highest electrical energy due to the presence of the highest wave intensity, followed by the beach of the Baysh and Al Morgan area.

Also, one of the objectives of this research is to study the design of a device powered by a buoy to use the waves of the Red Sea to generate electric power. The influence of the buoy system design parameters such as the buoy diameter, length of the cylinder, and the length of the connecting rod on the electrical energy generation from wave energy was investigated. The current device is designed with a gearbox to produce continuous power with a single electric generator. A floating mooring device uses the rise and fall of bulges to convert sea wave energy into electrical energy. The device consists of a float, arm, two wheels of different diameters, a gear set, and an electric generator. The effect of the design of several factors on the performance of the device for converting the sea waves energy into electrical energy, including the length of the buoy arm, the wave height by changing the cam diameter, and the conversion ratios between the gear set, to optimize the output power of the wave energy.
\end{abstract}

Keywords: Wave, Energy; Dynamics, Modeling; Generator; Converter, linear

\begin{tabular}{|ll|ll|}
\hline Nomenclature: & P & Wave energy power or flux, $\mathrm{kW} / \mathrm{m}$ \\
$\mathrm{A}$ & Area, $\mathrm{m}^{2}$ & $\mathrm{~S}$ & Spectral density function, $\mathrm{m}^{2} / \mathrm{Hz}$ \\
$\mathrm{a}$ & Amplitude of the wave & $\mathrm{S}$ & Net input energy, $\mathrm{kW}$ \\
$\mathrm{c}$ & Phase speed, $(=\mathrm{gT} / 2 \pi), \mathrm{m} / \mathrm{s}$ & $\mathrm{T}$ & Wave period, $\mathrm{s}$ \\
$\mathrm{d}$ & Sea water depth, $\mathrm{m}$ & $\mathrm{z}$ & Displacement of buoys motion, $\mathrm{m}$ \\
$\mathrm{E}$ & Wave energy spectrum density, W/Hz & $\sigma$ & Relative frequency, $\mathrm{Hz}$ \\
$\mathrm{f}$ & Wave frequency, Hz & $\theta$ & Wave direction \\
$\mathrm{g}$ & Acceleration of gravity, $\mathrm{m} / \mathrm{s}^{2}$ & $\phi$ & Latitude, degrees \\
$\mathrm{H}$ & Wave height, $\mathrm{m}$ & $\varphi$ & Velocity potential, $\mathrm{m}^{2} / \mathrm{s}$ \\
$\mathrm{h}$ & Wave depth, $\mathrm{m}$ & $\rho$ & Density of sea water, $\mathrm{kg} / \mathrm{m}^{3}$ \\
$\mathrm{~J}$ & Energy flux, W/m & $\lambda$ & Wave length, $\mathrm{m}$ \\
$\mathrm{k}$ & Wave number, $(2 \pi / \lambda), 1 / \mathrm{m}$ & $\omega$ & Angular frequency, $\mathrm{rad} / \mathrm{s}$ \\
$\mathrm{m}$ & Mass, kg & $\zeta$ & Vertical surface displacement, $\mathrm{m}$ \\
$\mathrm{M}$ & Spectral moment, $\mathrm{Nm}$ & $\tau$ & Momentum of flux, $\mathrm{J} /\left(\mathrm{m}^{2} \mathrm{~s}\right)$ \\
$\mathrm{N}$ & Wave action density spectrum, $\mathrm{m}^{2} / \mathrm{Hz}$ & $\omega$ & Angular frequency $\mathrm{rad} / \mathrm{s}$ \\
\hline
\end{tabular}




\section{Introduction and literature review}

Ocean and sea waves carry very large amounts of energy that can be used to generate electricity, which contributes to reducing global warming rates and reducing the demand for electricity produced from oil [1]. Globally, the resource's estimated wave power is more than 2 terabytes [2]. Abidur et al. [3] mentioned that nowadays, the use of sea and ocean waves to generate electric power is very common and futuristic. Omar et al. [4] conclude that the energy of the sea and ocean waves is one of the most reliable, powerful, and attractive renewable energy sources, it is equivalent to $\left(2-3 \mathrm{kWh} / \mathrm{m}^{2}\right)$, wind energy $\left(0.4-0.6 \mathrm{~kW} / \mathrm{m}^{2}\right)$, and solar energy $(0.1-$ $0.2 \mathrm{kWh} / \mathrm{m}^{2}$ ). Farrok et al. [5] state that wave energy has the most important renewable energy sources with many advantages compared to other types of renewable energies. In the northeastern region of Bari Island, the wave energy is $550 \mathrm{~J} / \mathrm{m} 2$ [6]. However, the use of these energies requires long beaches, and this is what characterizes the Kingdom of Saudi Arabia, where wave energy is obtained from converting the periodic movement of waves up and down from placing equipment on the surface of the water, then these mechanical energies are captured and converted into electrical energy. The Kingdom of Saudi Arabia [5,6] is aware of the importance of renewable energy such as solar energy, wind energy, and sea wave energy, and has huge oil resources. It is very interesting in taking an active role in developing new technologies to exploit and benefit from all kinds of renewable energies. Ralston et al. [7] concluded that waves are always high in most parts of the Red Sea and that the height of a large wave in its deep water ranges between 2.0 and 4.5 meters.

European countries have been at the forefront of ocean energy production [8], and in 2014, Bellamis produced around $250 \mathrm{MWh}$ of electricity for the UK grid [9]. Ocean Energy Technologies [10] built a raft that converts wave energy into electricity at a rate of 1 kilowatt using an electric buoy and a piston that rises and falls with the movement of the waves and is connected to an electric generator. The average wave power along the Indian coast is about $5-10 \mathrm{~kW} / \mathrm{m}$ and can produce $3750-7500 \mathrm{MW}$ when only $10 \%$ of its energy is used [11]. The total available wave power globally [12] has been estimated at 2.7-70 TW, and in the Red Sea region, it is 5-10 $\mathrm{kW} / \mathrm{m}$. Despite all of the above, the performance of many wave energy companies was weak due to their inability to generate electricity from these high-energy waves due to the dependence of the devices that were used on the wave dynamics [13-17]. But currently, there are many different types of ocean wave energy converters (WECs) that have been successfully tested [18-20] to convert wave energy into electrical energy.

On the other hand, the wave conversion energy devices can be either rotational or transitional, and each type has different characteristics [21-23]. The first type is linear generators (LGs), which convert wave energy directly without intermediate devices [24-26]. The second type is a transducer with thin floats, damping plate, and tensioned line system (which can provide good stability for better operating conditions) [27]. These devices are usually on or near beaches and produce power from $500 \mathrm{~kW}$ to $2 \mathrm{MW}$ depending on the size of the systems. The third type [28] is to use the forces of reciprocating waves to transform the energy of the waves into a rotating movement in the floating vertical columns through rotating gears directly with the electric generators. The fourth type [29] is based on transforming the energy of reciprocating waves into pistons and air pressure in the tubes into wind turbines into electric generators. OPT has developed a system of easy-to-install wave buoys to produce 10,100 megawatts of electricity from the shores of Australia at a cost of about 3-7 cents/kWh. Wave energy works about $90 \%$ of the time while solar or wind generators only work $20-30 \%$ of the time and this makes the economic yield of wave energy suitable for wide power generation. A system of buoys with wave energy transducer (WEC) was installed with measurements taken for 12 months [30], and the results showed that the energy produced did not vary with wave climate.

Despite the presence of the four previously listed, there is no data to compare between these types in terms of the best efficiency or the easiest to apply and the most capable of generating a greater amount of electrical energy, and therefore the work required in these topics is very large when applied with the highest efficiency systems. One of the objectives of this work is to determine the best location for the wave transducer on the shores of the Jazan region in the Red Sea. And deducing the most appropriate system for generating wave energy based on the information collected from satellite images and research published on this topic. Also, the effects of the wave depth, amplitude, length, and frequency are investigated. These parameters were evaluated along with environmental factors for sustainability development, site constraints, technical, and social impacts. 


\section{Wave energy resource assessment for the Red Sea}

From the interesting properties of the seawater is the wave speed is proportional to its length $(\mathrm{C}=\mathrm{gT} / 2 \mathrm{p})$. That is, longer waves will travel at higher speeds while the opposite is true for shorter waves. Wave energy is an intermittent energy source and Aboobacker et al. [31] concluded that the wave strength was calculated using the stopped wave parameters over 32 years, and the monthly, seasonal and annual wave strengths were estimated in the Red Sea. The results concluded that deep water gives the highest average wave power of $4.5 \mathrm{kWh} / \mathrm{m}^{2}$ in the fall. In winter, the power of wave energy is given up to $6.5 \mathrm{kWh} / \mathrm{m}^{2}$, in spring up to $5.0 \mathrm{kWh} / \mathrm{m}^{2}$, and in summer up to $4.5 \mathrm{kWh} / \mathrm{m}^{2}$. The highest mean wave energy is between seasons of Dec. to Mar, which is up to $6.5 \mathrm{kWh} / \mathrm{m}^{2}$, the lowest during Jul-Aug (up to $4.0 \mathrm{kWh} / \mathrm{m}^{2}$ ). The bottom of the Red Sea is characterized by the power of waves laden with energy. The highest long-range average wave energy located along the central coast of Saudi Arabia is estimated at $1.6 \mathrm{kWh} / \mathrm{m}^{2}$. Summer has the highest average wave power along the coast of Saudi Arabia with wave energy of $1.7 \mathrm{kWh} / \mathrm{m}^{2}$ in the central region. In all seasons, the southern part of the coast of Saudi Arabia responds with low average wave energy (up to $0.41 \mathrm{kWh} / \mathrm{m}^{2}$ ). In the monthly rating, the average wave strength is higher along the western coast of Saudi Arabia approximately and constant during the period from January to September. And weaker during the period from October to November. And they estimated that the trends are positive across all sites with an average increase in mean wave strength of $20 \%$, and under neutral conditions, the mean annual wave energy pattern is similar across all sites in the Red Sea, and this helps wave power converter (WEC) developers and operators in their decision.

It is not possible to predict the strength of waves and the time of their occurrence at a particular time, and this is the case for most renewable energy sources such as wind, waves, and the sun. Wind power is less intermittent than solar energy, and wind power at sea is less intermittent than wind power on land [32-34]. Wave energy is compared to wind energy, both because the two energy sources have a lot in common physically. The sea surface is lying on $x y$ plane, where $y$ component concerning zero as the wave propagates in $x$-direction, $d W$ is the water depth of the sea concerning $x y$ plane or water surface, the seabed is at $z=-d W$, and the sea surface coincides with $z=0$. Then the general description of sea wave is depending on the interpretation of $\zeta=A \cos (\mathrm{kx}-$ $\omega \mathrm{t})$, where $\omega$ is the frequency, $\left[\omega=\operatorname{gktanh}\left(\mathrm{kd}_{\mathrm{w}}\right)\right]^{0.5}$, that asserts the physics and describes consideration of a water wave relating frequency, $k$ is the number of waves $(k=2 \pi / \lambda \omega), v$ is the phase speed or sea wave velocity. Figure 1 shows the waveform and amplitude of the free seawater wave. Hence, the perpendicular distance between the wave crest and trough is $H$ which is twice the amplitude $A$.

Considering the phase speed which is a single basic wave that moves along the $x$-direction can be expressed is:

$$
v=\left[(\mathrm{gh} / 2 \pi) \tanh \left(2 \pi \mathrm{d}_{\mathrm{w}} / \lambda\right)\right]^{0.5}
$$

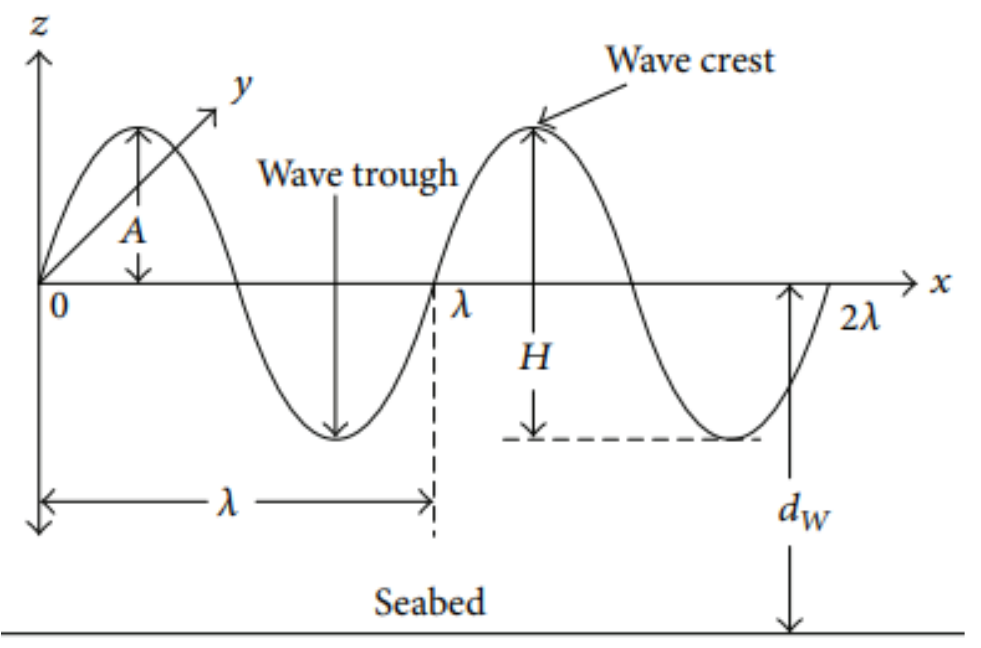

Fig.1: Waveform and amplitude of free seawater wave 
If the kinetic energy per unit length in $\mathrm{x}$ - direction is $\mathrm{Ek}$, then the particle kinetic energy of width $\mathrm{dx}$ is:

$$
\mathrm{dEkdx}=0.5 \mathrm{dxdy} \rho(\mathrm{r} \omega)^{2}=0.5 \rho \omega^{2} \mathrm{a}^{2} \mathrm{e}^{2 \mathrm{y}} \mathrm{dy}=\rho \omega^{2} \mathrm{a}^{2} / 4 \mathrm{k}
$$

The total energy of the wave is:

$$
\mathrm{dEk}=0.5 \rho \mathrm{a}^{2} \mathrm{~g}=\rho \mathrm{a}^{2} \mathrm{~g} \lambda / 4=\rho \mathrm{a}^{2} \mathrm{~T}^{2} / 4 \pi
$$

The power associated with the wave per unit width, $(\mathrm{P} / \mathrm{h}=\mathrm{W} / \mathrm{m})$ is:

$$
\mathrm{P} / \mathrm{h}=(1 / 8 \pi) \rho \mathrm{a}^{2} \mathrm{~g}^{2} \mathrm{~T}
$$

Based on the conservation of energy, since the source is the wave energy stream, the rate of change of the wave energy spectrum $\mathrm{E}(\mathrm{k})$ can be expressed [35] as:

$$
\mathrm{dE}(\mathrm{k}) / d t=-\left[2 \mathrm{k} \sigma E(\mathrm{k}) /\left(g \sinh ^{2} \mathrm{k} d\right)\right] \int_{-d}^{0} \tau \mathrm{k} \sinh \left(2 \mathrm{k} z+2 \mathrm{k} d^{2} d z\right)
$$

And in case of deep-water waves, Equ.5 becomes:

$$
\mathrm{dE}(\mathrm{k}) / \mathrm{dt}=-4 \mathrm{k} \sigma E(\mathrm{k}) / g \int_{-d}^{0} \tau \mathrm{k} e^{2 \mathrm{k} z} d z
$$

Equation-6 shows the appropriate description of the waveform change based on the appropriate description of the turbulence changes on the wavelength scale, including the short-wave fraction modulation of the long-wave. The deep sea water dispersion relation can also be used to find a relationship between the wave length and the period of a wave. The phase speed which moves along the $x$-direction can be expressed as:

$$
\left.c_{\mathrm{p}}=\left[(\lambda \mathrm{g} / 2 \pi) \tanh \left(2 \pi \mathrm{d}_{\mathrm{W}} / \lambda\right)\right)\right]^{0.5}
$$

According to Faraday's law, the induced voltage of the wave is:

$$
E_{i}(t)=-N d \Phi / d t
$$

According to marine scientists, it is considered a linear wave, where the sea surface is lying on $x y$ plane, $y$ components are considered zero as the wave propagates in $x$-direction, $d_{W}$ is the water depth of the ocean concerning water surface ( $x y$ plane), the seabed is at $z=-d_{W}$, and the ocean surface coincides with $z=0$. If the velocity potential is defined as, $\phi=(\mathrm{gh} / 2 \omega) \mathrm{e}^{\mathrm{kz}} \sin (\mathrm{kx}-\omega \mathrm{t})$, The flux variation concerning time can be expressed as:

$$
\Phi(t)=2 \pi \Phi d_{\mathrm{tr}}(t) / \lambda
$$

The wave energy flux over the depth is described by pressure times velocity which can be written as integrate will give an expression for the flux per meter of wave crest:

$$
J=-\int_{-\infty}^{0} p v_{x} d z
$$

Combining Equs. (3-8 and 10), the average generated wave energy flux becomes:

$$
\mathrm{J}_{m}=4 \pi^{2} A_{w} \mathrm{k} N \Phi / \lambda T=\rho \mathrm{g}^{2} \mathrm{H}^{2} \mathrm{~T} /(32 \pi)
$$

Where $\mathrm{p}$ is the pressure, and if, the constant $\rho^{2} /(32 \pi)$ is denoted $\alpha$ in Equ. (11), using Equ. (7), the average generated wave energy flux can be written as:

$$
\mathrm{J}_{m}=\alpha \mathrm{kEc}_{\mathrm{p}}=\rho \mathrm{g}^{2} N \Phi /(16 \lambda)\left[(\lambda \mathrm{g} / 2 \pi) \tan (\mathrm{h})\left(2 \pi \mathrm{d}_{\mathrm{W}} / \lambda\right)\right]^{0.5}(t)
$$

However, the wave period (T) can be generated by using, T=3.55h0.5 (s), and the wave length $(\lambda)$ can be generated by using $\lambda=5.12 \mathrm{~T} 2(\mathrm{~m})$, which equals $64.5248 \mathrm{~h}(\mathrm{~m})$. Figure 2 shows the effect of the sea waves period and height on the energy flux and production. It is noted from the figure that the energy produced by the waves increases with the increase in the height of the waves and decreases with the increase of the wave period. It should be mentioned here that the wave energy was calculated using the wave data and the number of occurrences of each wave condition according to the laboratory results of Rafael et al. [35]. The sea wave energy and power respectively can be written as the following:

$$
\mathrm{E}_{\mathrm{w}}=32.3 \rho \mathrm{whga}^{2}, \mathrm{E}_{\mathrm{wd}}=0.5 \rho \mathrm{ga}^{2}
$$

And,

$$
\mathrm{P}_{\mathrm{w}}=0.28 \mathrm{~h}^{2} \mathrm{E}_{\mathrm{w}}, \mathrm{P}_{\mathrm{wd}}=\mathrm{h}^{2} \mathrm{E}_{\mathrm{wd}}
$$




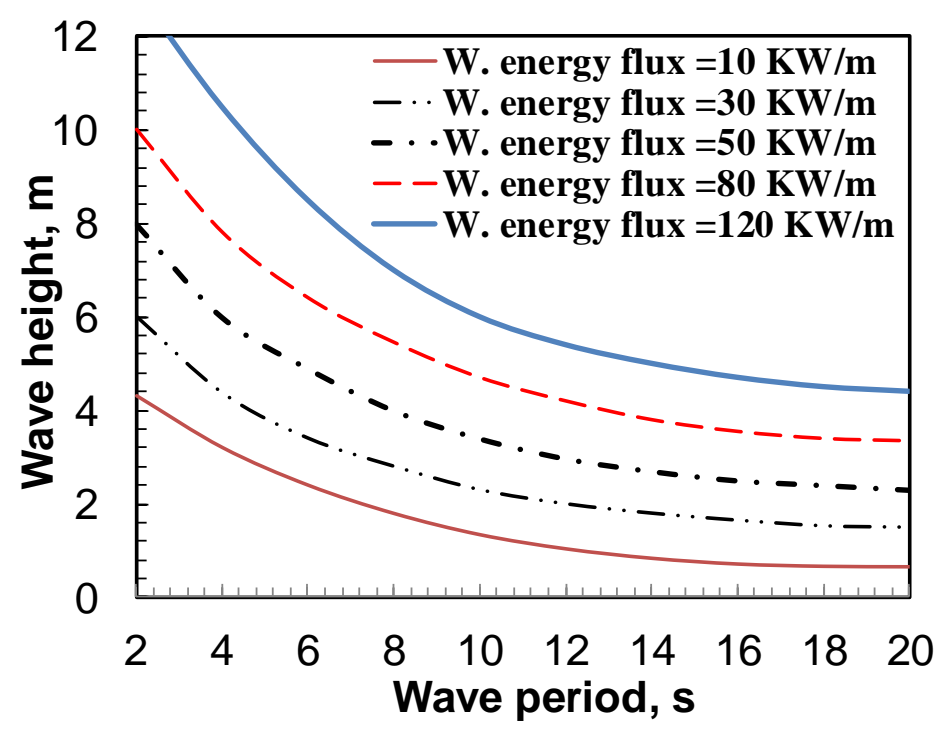

Fig. 2: Effect of sea wave period and height on the energy flux or production

Where $E_{w}$ is the wave energy, $w$ is the wave reflector length, $E_{w d}$ is the wave energy density that can be harvested per area of the wave, $\mathrm{P}_{\mathrm{w}}$ is the power that can be produced by sea waves, and $\mathrm{P}_{\mathrm{wd}}$ is the power density that can be harvested per area of the wave. In the conditions of the deep water with assuming, $\mathrm{k}=\omega^{2} / \mathrm{g}, \mathrm{cg}=\mathrm{g} / 2 \omega, \mathrm{T}=2 \pi / \omega$, the total sea wave power $\mathrm{P}$, using Equ. 14 is:

$$
\mathrm{P}=\rho \mathrm{g}^{2} \mathrm{H}^{2} \mathrm{~T} /(64 \pi) \approx 0.55 \mathrm{H}^{2} \mathrm{~T}
$$

The power concerning the height and period of the wave as well as the specific power of the wave per width can be calculated according to the standards of the transient water in watts per meter as follows:

$$
P_{w}=\left(\rho g H^{2} / 32\right)[1+\tanh (\mathrm{k} d)]\left[\sqrt{\frac{g}{k} \tanh (k d)}\right][1+2 \mathrm{kd} / \sinh (2 k d)]
$$

Using Equ. 16, for a given wave period and height, the wave power per meter can be evaluated of the crest of that wave as shown in figure 3. It is clear from the results that the power produced from sea waves is not constant, but it has maximum values of about $1.5 \mathrm{~kW} / \mathrm{m}$ and minimum values close to zero, and the estimated average power of about $0.43 \mathrm{~kW} / \mathrm{m}$. This fluctuation in the wave power is due to the intensity of wind speed. In general, the power generated is greater than that of more powerful waves, which is determined by knowing the length and velocity of the wave and from the density of the water. Mathematically, wave power is determined by wave power equations whose factors are wave energy or wave energy flow and wave energy transfer rate. In general, in deep water, the two scientists consider the depth of water to be greater than half the wavelength. Robertson et al., [37] have been estimated the global wave energy of $2.11 \pm 0.05 \mathrm{TW}$. Figure 3 shows the power generated by the waves result of the current model and measurements of Rafael [35], with an acceptable agreement. The average power of the sea waves is about $24 \%$ of the first load configurations of the buoy.

\section{Numerical wave modeling}

At present, numerical models are one of the most powerful tools for studying seawater waves and dams and predicting their energy. Also, they have proven to be an essential tool for the design and protection of coastal structures and as a life-saving tool during hurricanes and storms [38]. On the other hand, due to the irregular behavior of the sea waves, which have varying intensities, the intensity of the contrast E(f) can be written instead of Equs. 8 and 10 as $E(f)=0.5 a(f)^{2} \Delta$ f. And the energy of the omnidirectional wave $(J)$ that can be transferred as the energy passes through a cylinder of a hypothetical unit diameter can be written as:

$$
J=\rho g \sum_{i} c_{g, i} E_{i} \Delta f_{i}
$$



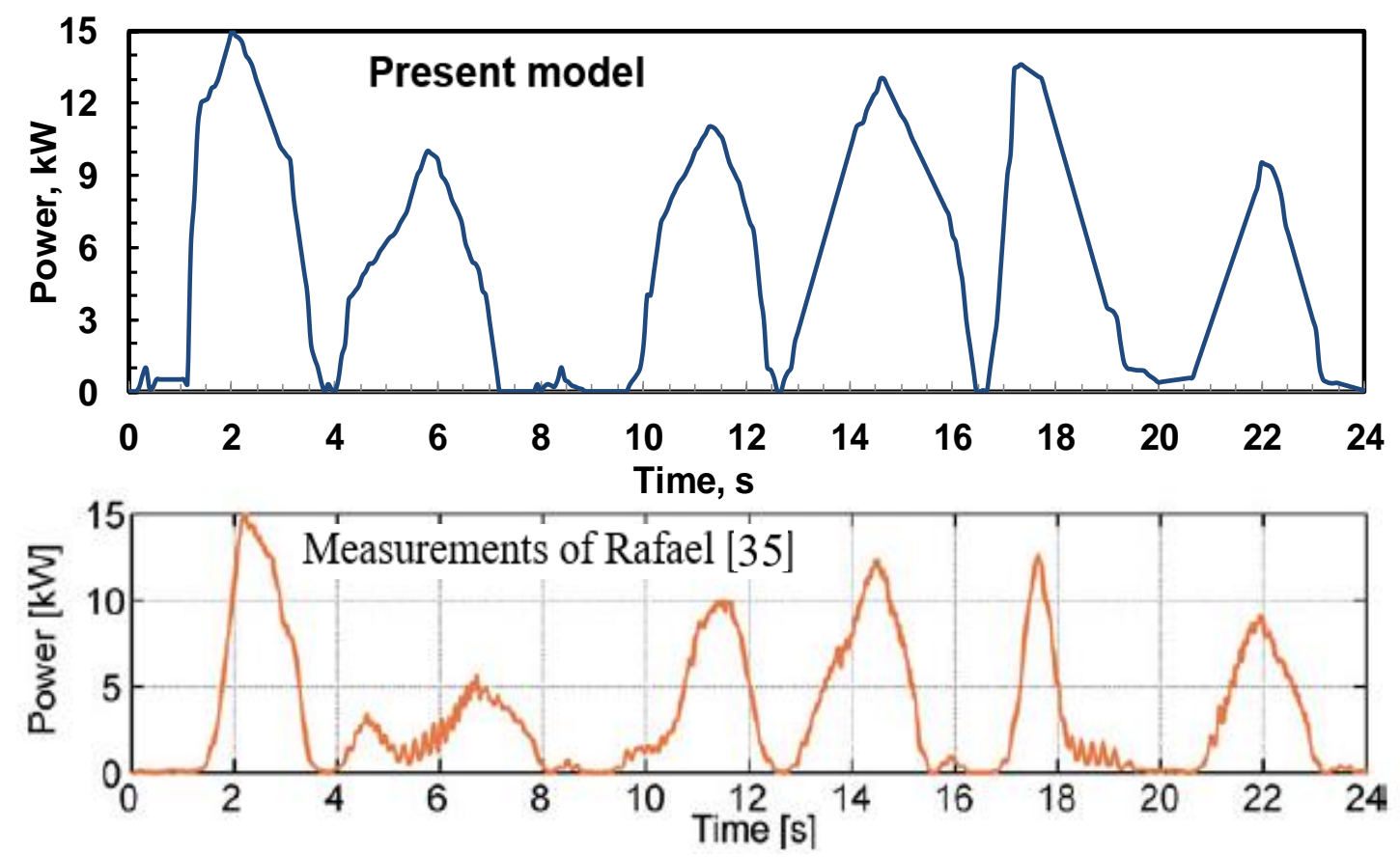

Fig. 3: Extracted wave power per unit area from the present work and Exp. [35]

Where, $c_{\mathrm{gi}}$ is the wave group velocity, $\left(\mathrm{c}_{\mathrm{gi}}=\left(\pi \mathrm{f}_{\mathrm{i}} / \mathrm{k}_{\mathrm{i}}\right)\left[1+2 \mathrm{k}_{\mathrm{i}} \mathrm{h} /\left(\sinh \left(2 \mathrm{k}_{\mathrm{i}} \mathrm{h}\right)\right]\right), f_{i}\right.$ represents the $i^{\text {th }}$ wave frequency in the spectrum, $\Delta f_{i}$ is the frequency bandwidth, $k_{i}$ is the wave number $(2 \pi / L)$ and $h$ is the water depth. Most of the factors that are used to describe the spectra of waves depend on the spectral moment $\left(\mathrm{M}_{\mathrm{n}}\right)$, which be written as:

$$
M_{n}=\sum_{i} f_{i}^{n} E_{i} \Delta f
$$

And if the height of the zero-momentum wave $\left(\mathrm{H}_{\mathrm{mo}}=4 \sqrt{ } \mathrm{M}_{\mathrm{n}}\right)$, is considered, the total energy of sea waves from all directions at the same time (directed wave energy, $\mathbf{J}_{\theta}$ ) is:

$$
J_{\theta}=\rho g \sum_{i, j} c_{g, i} s_{i, j} \Delta f_{i} \Delta \theta_{j}\left(\theta-\theta_{j}\right) \delta\left\{\begin{array}{l}
\delta=1, \cos \left(\theta-\theta_{j}\right) \geq 0 \\
\delta=0, \cos \left(\theta-\theta_{j}\right)<0
\end{array}\right.
$$

Equation 19 indicated that the weighting of the cosine function and $\mathrm{J} \theta$ take priority for wave systems whose directions have the height energy transfer and minimize the effect of low wave energy flow from transverse directions. Provide the coefficient $\mathrm{d}(=\mathrm{JqJ} \mathrm{Jax} / \mathrm{J})$ the directional of spreading wave in the directional of the space, and $\epsilon_{0}$ the measure of the spreading wave across the frequency space. Langodan et al. [39] mentioned that all large mathematical models underestimate the energy produced from sea and ocean waves, which led to a lack of great interest to produce electricity from them, and this is what laboratory experiments have proven the opposite. When the wave conditions are known within 20 minutes, the wave power can be evaluated using Equ.15, and substitute, $\mathrm{P}=0.55 \mathrm{H} 2 \mathrm{sTz}, \mathrm{kW} / \mathrm{m}$, the average height of the wave $\mathrm{Hm}$, and the height of the big wave Hs (average top $33 \%$ of waves). Figure 4 introduces a comparison between the results of the current model and practical measured by NDBC buoys of [29], and what they stated is confirmed in this figure. It is noted in this figure that the spectra of high-frequency energy waves are few, despite the high value of energy production from these waves, which proved that the cost of kilowatt-hours is lower than that of wind, solar, and hydraulic energies as mentioned in the reports of researchers in this field $[4,5,11,12]$. 


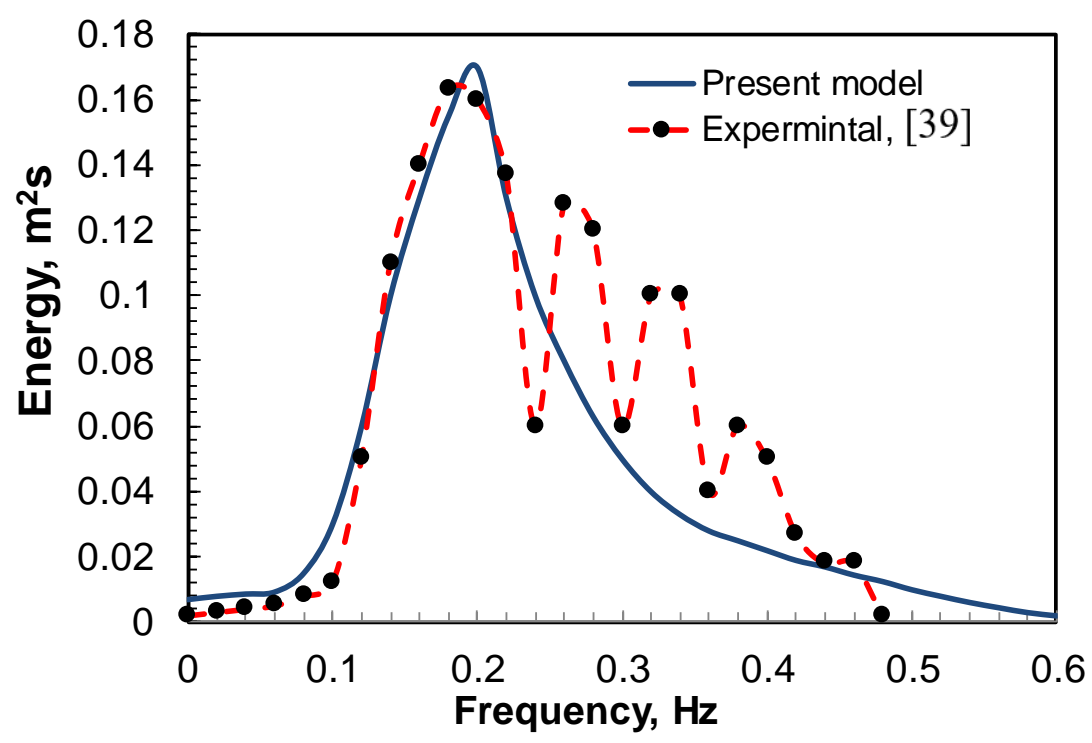

Fig. 4: Comparison between results of the present model and measured [39]

\section{Estimation of Power Associated with Waves}

The intensity of the Doppler spectrum can be written based on the spectral theory of Doppler in the case of wave height within the cross-section as follows:

$$
\mathrm{I}(\omega)=\left(2 \sigma \pi^{2.5} \mathrm{~V}_{\mathrm{S}} \mathrm{T}_{\mathrm{S}} / \mathrm{h}^{2}\right) \exp \left[-(2 / \mathrm{bt})^{2} \omega^{2}\right] \times \exp \left[-(2 / \mathrm{bt})^{2}\left(\omega-\omega_{\mathrm{d}}\right)^{2}\right]
$$

And the generated voltage can be written as:

$$
\mathrm{V}_{\mathrm{g}}(t)=V_{m} \cos (2 \pi \mathrm{t} / T) \cos \left\{\left(2 \pi A_{w} / \lambda\right) \sin (2 \pi \mathrm{t} / T)\right\}
$$

Using Equs. $(20,21)$ the sea wave generated power as a function of time and period can be evaluated. Figure 5 shows the effect of wave period on the wave energy absorption efficiency of buoys system at buoy boom length of $8.0 \mathrm{~m}$, a radius of $1.0 \mathrm{~m}$, and damping coefficient of hydraulic system $5.0 \times 104 \mathrm{~N} / \mathrm{sec} / \mathrm{m}$. It is clear from the figure that the absorption power of the device and the power of the incoming wave are varying with the period of the wave, and that the power of the incoming wave increases with the increase of the period of the wave. The absorbing capacity of the wave energy from buoys and the hydraulic system is maximum when the wave period is 3.7 seconds and 3.2 seconds respectively and then starts to decline. Figure 5 shows the Red Sea mean wave period through a year from the results of the present model, measured and theoretical of Aboobacker et al. [31]. The figure shows the different values of the wave period during the various months due to the changes in the speeds and strengths of sea waves resulting from the variations in the wind speed that is completely associated with it. The figure shows that the average in some months differs from other months, i.e., the wave period January is weak, but in July it is strong. Every month, a change in the wave force is observed from one day to another day, and the results of the current theoretical model and laboratory results of Aboobacker et al. [31] are in agreement despite some minor differences in the severity of the mortality for some days. The average mean wave period in the present model is at about $4.3 \mathrm{~s}$ while the experimental at $4.6 \mathrm{~s}$. The maximum values of the mean wave period are about $8 \mathrm{~s}$ and the minimum is about 2 in the experimental and model.

Figure 6 shows the effect of wave height on the power generated from the sea wave of the present model and experimental data of Rafael [35]. The figure show increases in wave-generated power period energy produced by waves at different heights of these waves. The figure shows when the waves height increase, the resulting power increases steadily. The laboratory results of Rafael [35] and the current theoretical model give an approximation to the results. Rafael et al. [41] found that the average power flux is about $5.2 \mathrm{~kW} / \mathrm{m}$ at offshore Skagerrak of Sweden, $2.8 \mathrm{~kW} / \mathrm{m}$ near Skagerrak beach, and $2.4 \mathrm{~kW} / \mathrm{m}$ at Kattegat. 

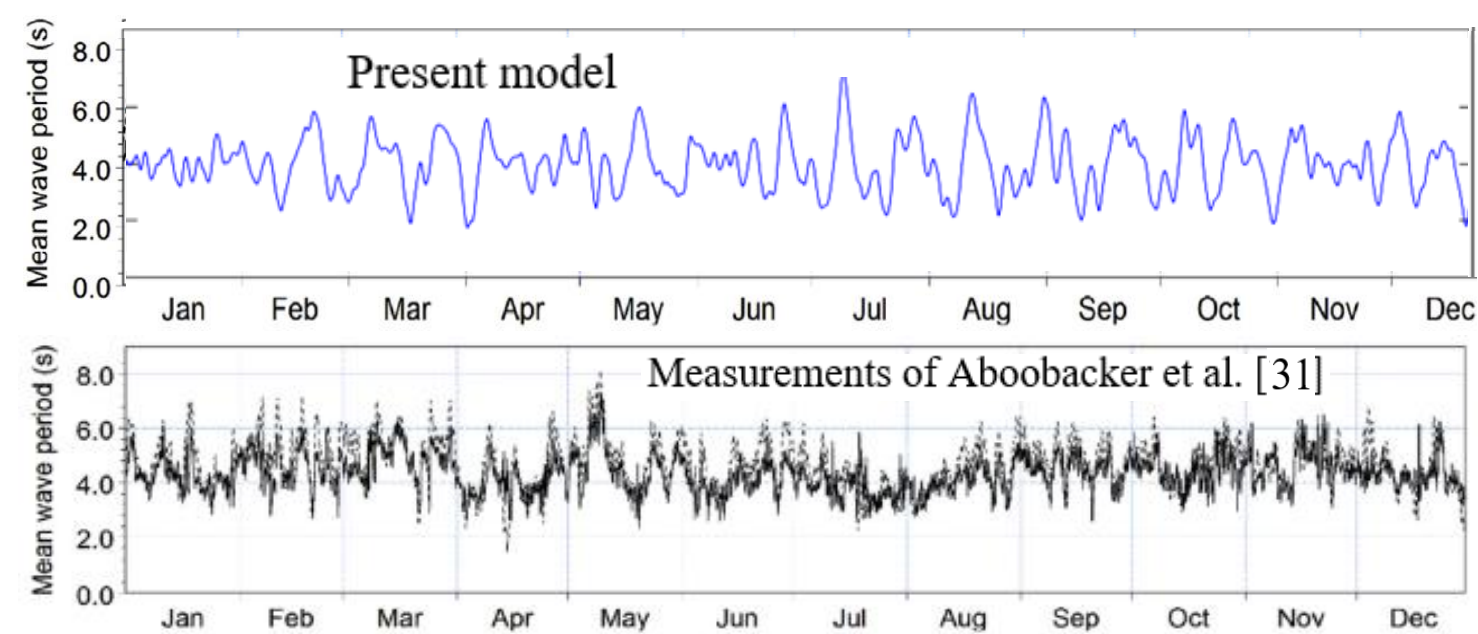

Fig. 5. Comparison between the results of the present model and measurements of Aboobacker et al. [31].

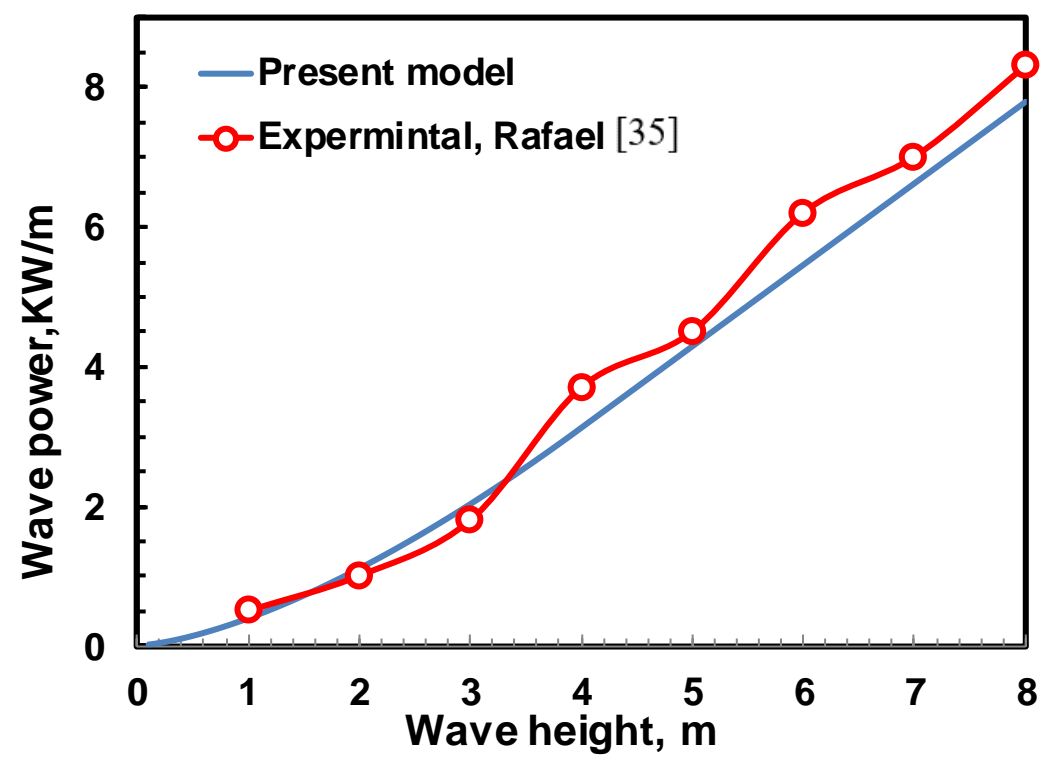

Fig.6: Effect of wave height on the sea wave power from the present model and Exp. [35]

While the average power flux above $55 \mathrm{~kW} / \mathrm{m}$ (ten times the general average) only during 7 days of the 8 years studied and exceeds $100-250 \mathrm{~kW} / \mathrm{m}$ only during half an hour (the highest 45 times the overall average). But the power flow reaches above $13.5 \mathrm{~kW} / \mathrm{m}$ only $10 \%$ of the time. Almost $50 \%$ of the total energy is found in offshore nations with a large wave height between 1 and 3 meters and a power period between 4 and 7 seconds. Figure 7 shows [33] the geographical study area: 32 e44 E; 12 AH 30 from the Red Sea and has an area of about 38000 square kilometers, with a length of about $2,300 \mathrm{~km}$ and a width of $360 \mathrm{~km}$ in the widest part. The average depth is about $490 \mathrm{~m}$, the maximum depth is $2920 \mathrm{~m}$, and the average wind speed is $10-15 \mathrm{~m} / \mathrm{s}$. The figure shows coastal locations on the Red Sea where the average wave power is calculated from typical wave scales. This region was divided into several locations along the Red Sea, west of Saudi Arabia and Yemen, and the east coast of Egypt, Sudan, and Eritrea. From the collected data of satellite images, the values are shown in the maps published in Fig.7, that published by the researcher Aboobacker et al. [23], and using the above-mentioned equations in the current work, the sea wave produced energies in the Jazan area in the period from 2012 to 2021 is assessed, and represented in the figures 8 and 9 . 

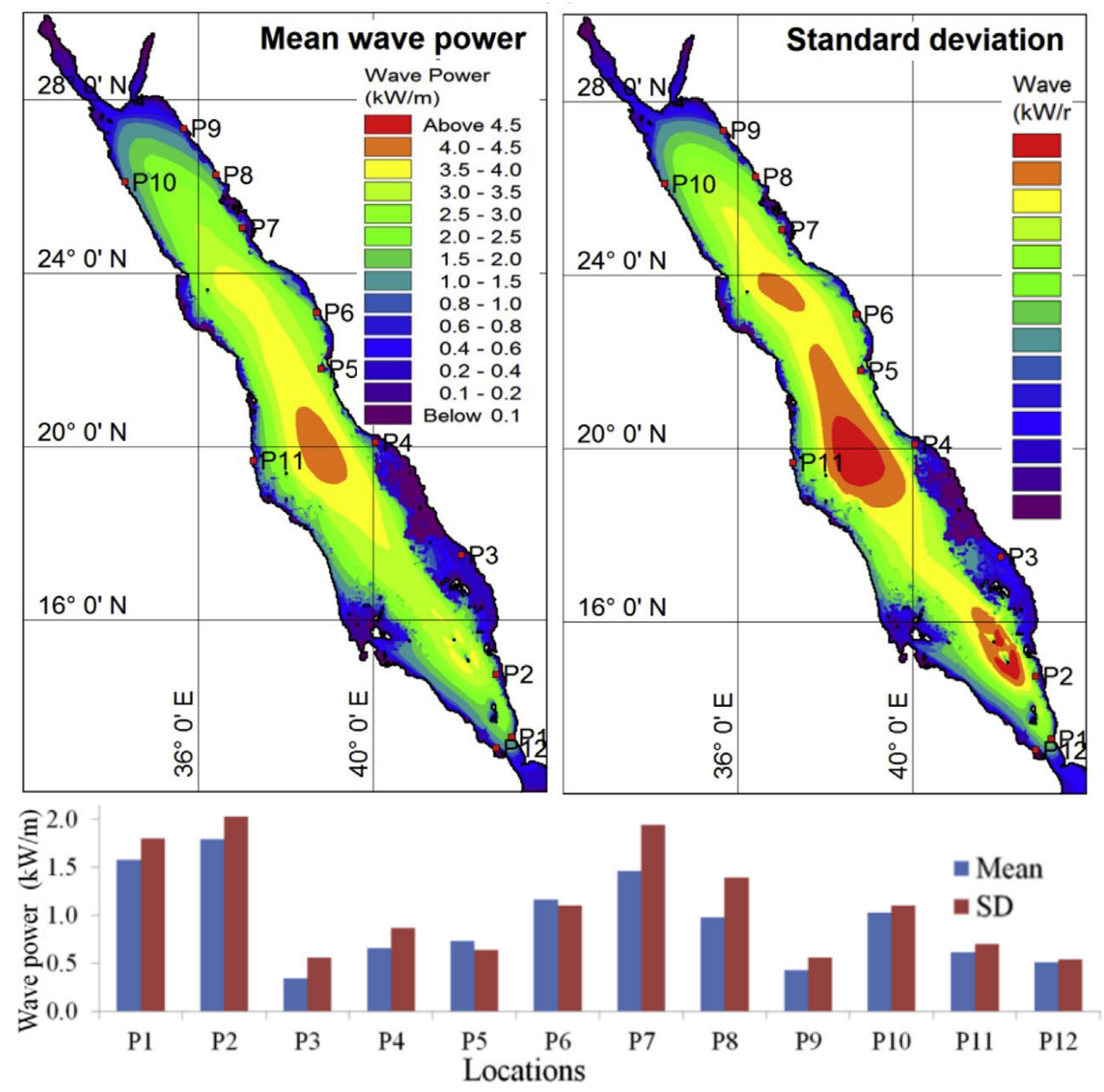

Fig. 7: Spatial distribution of mean wave power $(\mathrm{kW} / \mathrm{m})$ and standard deviation at different locations [33]

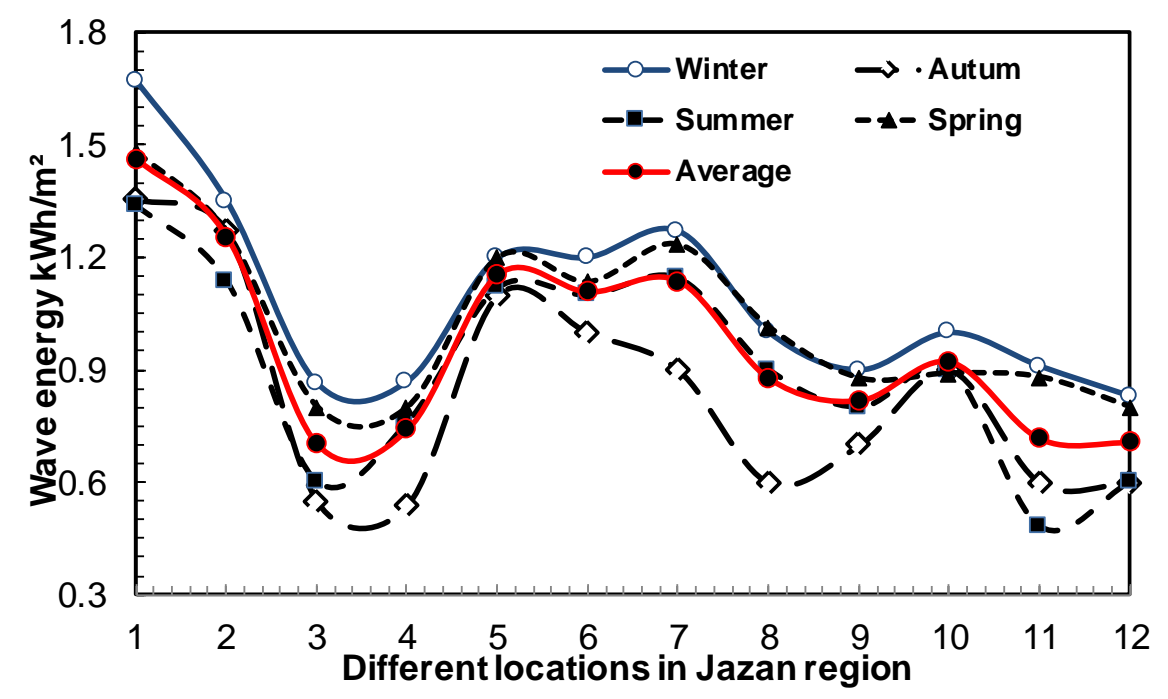

Fig. 8: Sea wave energy in sea wave energy at a different location 


\section{Estimation of the Red sea wave energy in the Jizan region}

Data were collected from satellite images and previously published research [12, 33, 35, 39 - 41] on the power of the Red Sea waves. Some locations of those are selected at Jizan city from the north to south of the red sea as the following: Al Shuqaiq beach B1, Bayesh beach B2, Al Tarfa beach B3, Al Hizam beach B4, Al Murjan Beach B5, Al Madaya beach B6, Al Mawasem beach Y7, Farasan Island beach B8, Muharraq beach B9, Janaba beach B10, Al Khattab beach B 11, Saber beach B12. The data of sea wave energy in the specified places from B1 to 12 for the beaches of Jizan city for the different seasons were represented in Figure 8, which shows that the intensity of wave energy on Al Shuqaiq beach L2 is the highest for the study areas followed by Al Murjan Beach B5, then Al Madaya 6. Figure 8 shows the highest wave energy at the location Al Shuqaiq beach B1. It is clear from Fig.9 that the highest sea wave energy is in January and December and decreases during the summer season.

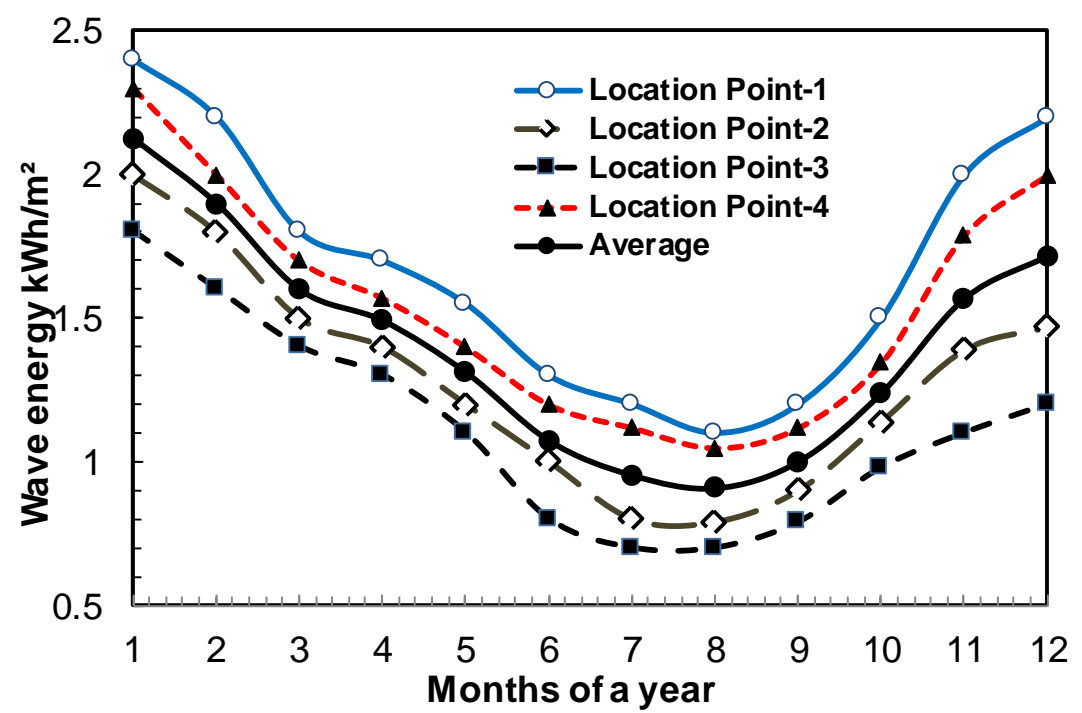

Fig. 9: Wave energy through a year for different four locations

\section{Variation of wave energy absorption efficiency with the radius of the buoy}

Since the sea wave energy depends entirely on wind energy, which is very large in the Kingdom of Saudi Arabia, so many researchers confirmed that wave energy is promising economically in this country [4244)]. The effect of the diameter and tensioned conduction line of the buoy which is used to generate electricity from sea waves on its performance was studied [45-49]. And because the speed of a wave is proportional to its length so the longer waves will travel at higher speeds and vice versa for shorter waves. Wang et al. [51] reported that the buoy has an efficiency of $98 \%$ of wave energy when it has a radius of $1.8 \mathrm{~m}$ and produces slight harmonic vibrations affected by forces in the vertical direction. To study the power output from a floating transformer system consisting of a cylindrical transformer and a hydraulic transformer partially immersed in seawater. The force can be written according to Newton's second law respectively as [52]:

$$
\left(\mathrm{m}+\mathrm{m}_{\mathrm{w}}\right) \ddot{\mathrm{y}}=\mathrm{F}_{\mathrm{C}}+\mathrm{F}_{\mathrm{S}}+\mathrm{F}_{\mathrm{V}}
$$

Where $m$ is the mass of the buoy, $m_{w}$ is the mass added of the buoy $\left(m_{w}=\pi \rho R^{2} / 2\right), F_{C}$ is the equivalent damping force $\left\{F_{C}=\left[\left(-8 C R^{2} / L^{2}\right)(1-r) y\right]\right\}, \quad F_{S}$ is the hydrostatic restoring force $\left(F_{S}=\rho g Y A_{w P}\right), F_{V}$ is the wave force $\left(F_{V}=F_{0} \cos \omega t\right), F_{0}$ is the amplitude of wave force that can be solved by the methods of theoretical analysis or, $\omega$ is wave circular frequency, $\ddot{y}$ is the heaving motion accelerated speed, $A_{W P}$ is the buoy wetted surface $\left(A_{W P}=2 L\left(2 d R-d^{2}\right)^{0.5}\right), d$ is the buoys immersed depth, $L, R$, are the buoy cylinder length and radius respectively, $C$ is the damping coefficient, $\left(\mathrm{C}=\mathrm{v}_{\mathrm{c}} / \mathrm{f}\right), \mathrm{f}$ is the hydraulic damping force, $\mathrm{v}_{\mathrm{c}}$ is the speed of hydraulic cylinder piston, $\mathrm{r}$ is introduced as the proportionality coefficient of speed $\left(\mathrm{r}=\hat{y}_{\mathrm{o}} / \mathrm{y}\right)$, y is the displacement of buoys heaving motion, and ý the speed. Using the above definition of the different forces with Equ.22, the equations of motion of buoys can be written as: 
$F_{0} \cos \omega t=\left(m+m_{w}\right) \ddot{y}+\left(-8 C R^{2} / L^{2}\right)(1-r) \dot{y}+r g Z A_{w P}$

, the buoy wave energy absorption power, $\mathrm{P}_{\mathrm{c}}$ can be written as:

$$
\left.P_{C}=(C / T) \frac{C}{T} \int_{0}^{T}[2(1-r) R \dot{y}) / L\right]^{2} d y
$$

and the wave energy absorption power of buoys is:

$$
P_{F}=\frac{1}{T} \int_{0}^{T} F_{V} \dot{y} d t
$$

It is possible to estimate the variation in the absorption power and the incoming wave power with the wave period with the buoy and hydraulic systems using Equs. 22-23. The results of the present solution at the condition of buoy length of $8.0 \mathrm{~m}$, the radius is $1.0 \mathrm{~m}$, and the damping coefficient of the hydraulic system is $5.0 \times 104 \mathrm{~N} \cdot \mathrm{s} / \mathrm{m}$ at different wave periods are shown in figure 10. The effects of the wave period on the wave incoming power, buoys, and hydraulic system are shown in the figure. The figure shows that the wave energy absorption power of the floats is maximum when the wave period is 3.6 seconds and 3.2 seconds respectively and then starts to decline. Therefore, the power of the incoming wave is a secondary factor that affects the dynamic responses of wave-capturing floats at a fixed wave height. Figure 11 shows the effect of buoys length on the average generated output powers according to the model. So we can get the conclusion that the model that we established in this paper is effective and available. The figure shows the buoys and the hydraulic system energy absorption power of the wave reaches its maximum at a submerged depth of about $1.5 \mathrm{~m}$ begins to drop sharply and reaches less than $10 \%$ at a submerged depth exceeding $1.8 \mathrm{~m}$. It can explain that because the growth rate of the wave force exceeds the growth rate of the mass inertia in the initial stages, the area of the immersed float decreases rapidly that leading to a decrease in the wave force. It means the efficiency drops more quickly due to the combined action of lower wave power and greater mass inertia. The power output from the wave increases with the increase of the wave height and buoy length as well as radius. The sea wave energy conversion efficiency can be expressed as the wave energy absorption efficiency similar to Ruellan et al. [53] and using Equs. 22 - 25 as:

$$
\eta_{\mathrm{f}}=\mathrm{P}_{\mathrm{F}} / \mathrm{P}_{\text {Sea }} \text {, and } \eta_{\mathrm{c}}=\mathrm{P}_{\mathrm{C}} / \mathrm{P}_{\text {Sea }}
$$

Where, $\eta_{\mathrm{F}}$ and $\eta_{\mathrm{C}}$ are the wave energy absorption efficiency of buoys and hydraulic system respectively, $\mathrm{P}_{\mathrm{F}}$, and $\mathrm{P}_{\mathrm{C}}$ are the average wave energy absorption power of buoys and hydraulic system, $\mathrm{P}_{\text {Sea }}$ is the input power of the wave, $\left(\mathrm{P}_{\text {Sea }}=\rho g^{2} \mathrm{BTH}^{2} / 32\right)$ [54], $\mathrm{B}$ is the immersed width of buoys. Figure 12 shows the effect of buoy radius on the efficiency of the wave energy absorption efficiency. It is in the figure that both wave energy absorption efficiency of buoys and hydraulic systems attain their maximum when its radius is about $1.8 \mathrm{~m}$. The maximum efficiency of the wave energy absorption of the buoys and hydraulic systems is $98 \%$ and $80 \%$ respectively.

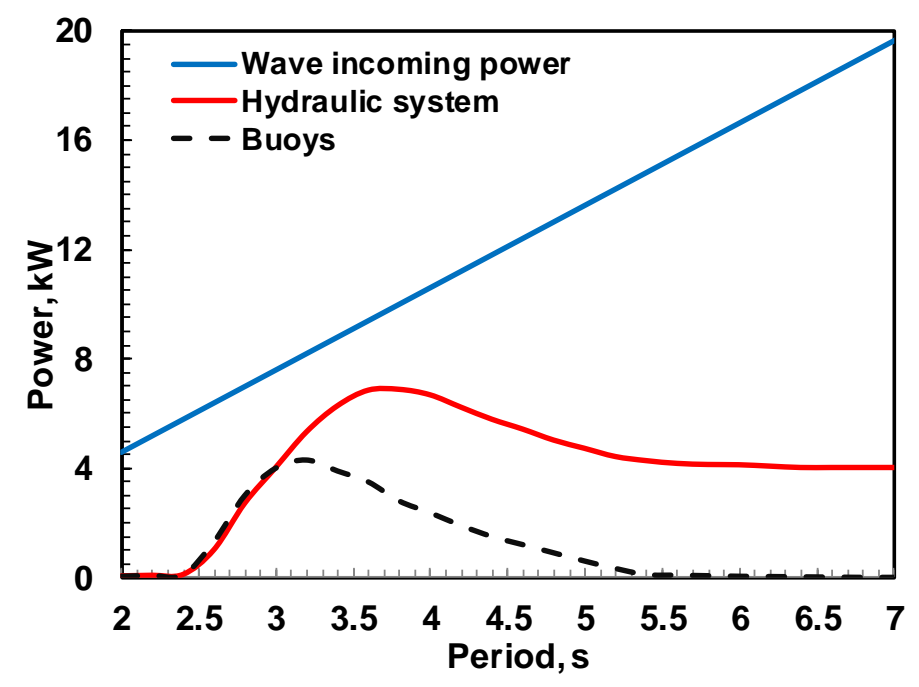

Fig.10: Variation of absorbing power of device and incoming wave power with wave period 


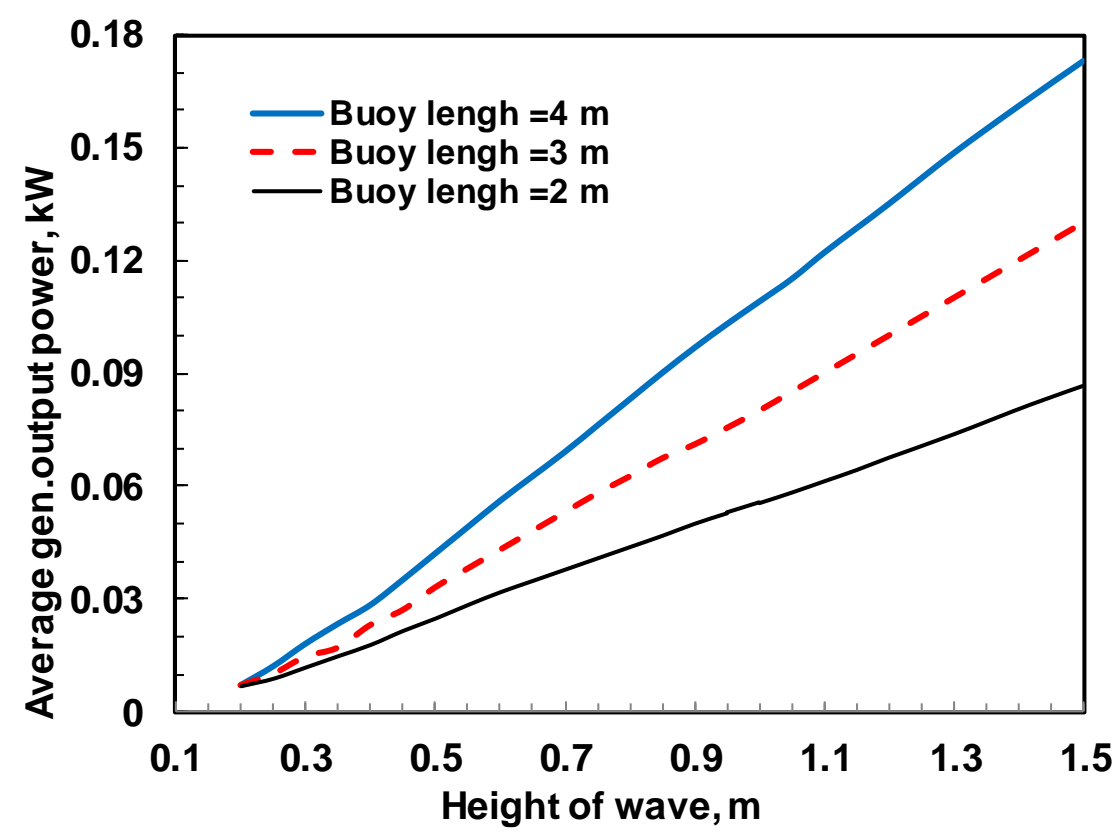

Fig.11: Effect of buoy length and wave height on wave average generation output power

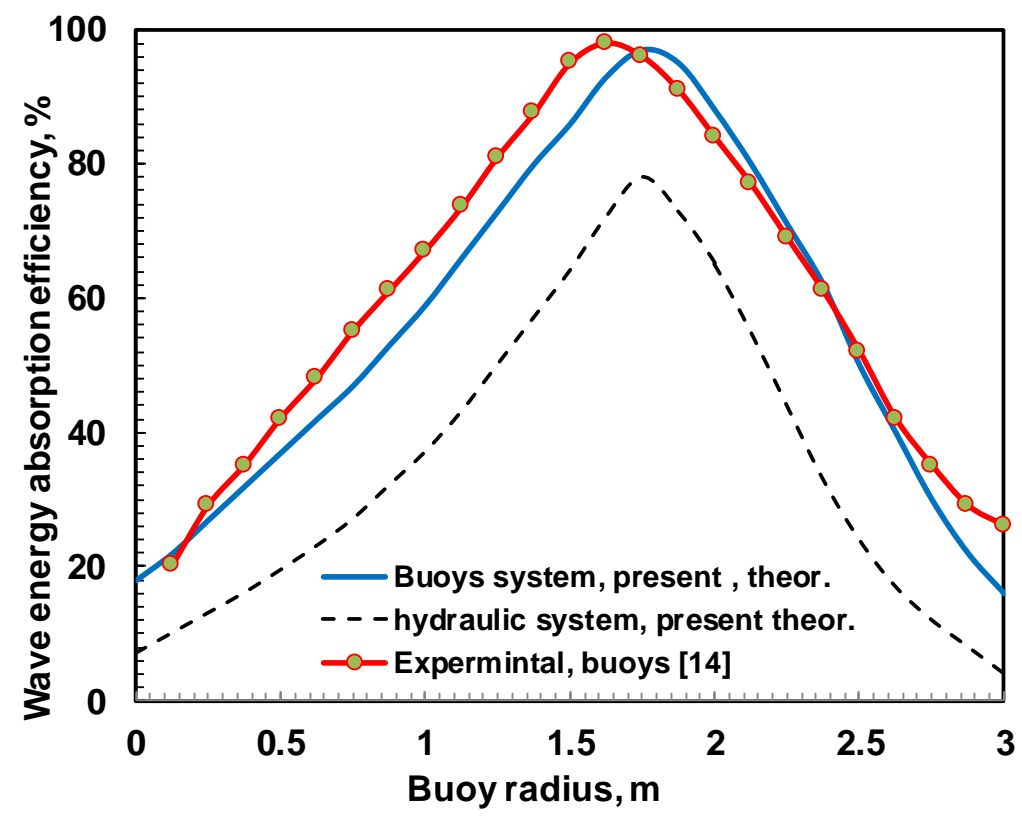

Fig. 12: Effect of buoy radius on the wave energy absorption efficiency

\section{Conclusions}

This research studies the use of the waves energy of the Red Sea shores of Jazan city to generate electric power using the system of buoys. The buoy motion was derivative according to the wave parameters factors of Newton's second law and on the linear wave theory. The weather assessment of the wave off the western coast of Jizan, Saudi Arabia was assessed based on the compilation of data from satellite imagery and published research for 10 years for 12 sites. Several twelve places along the coasts of Jizan city using satellite images and published research was surveyed to find the most suitable places for the highest wave energy. Effect of buoy system design 
parameters that effects the efficiency of absorbing wave energy were discussed. It was found that the buoy design factors such as the length, radius of the buoy, and the submerged depth of the buoy are of great importance for the absorption of the wave energy.

It was found that the beach of $\mathrm{Al}$ Shuqaiq area is the best place from the beaches of Jizan city to install the buoy and obtain the highest electric energy due to the presence of the highest wave intensity, followed by the beach of the Baysh and Al Marjan area. The highest marine energy endurance case with an average power flux of $1.0 \mathrm{~kW} / \mathrm{m}$ was found at Al Shuqaiq Beach. Wave heights are annually found in the interval 1-3 m and energy intervals in the period of 4-7 s. The wave energy absorption power of the floats is maximum when the wave period is 3.6 seconds and 3.2 seconds. The results showed that the main factor affecting the dynamic responses of wave-capture buoys is the proximity of the natural frequency of buoys to the wave period. The length and radius of the buoy are the most important factors influencing the design of the buoys to increase the energy of the waves, along with the submerged depth of the buoy. The present theoretical results were compared with the laboratory results of the published research and showed agreement to an acceptable degree.

\section{References}

1. Vivekraj M., "Design and Development of Ocean Wave Energy Power Generation System", Int. J. of Eng. Res.\& Tech. (IJERT), Published by: www.ijert.org Vol. 10, Issue 03, March 2021.

2. Gunn K., Stock-Williams C., "Quantifying the global wave power resource”, Ren. Energy.44, 296e304, 2012.

3. Abidur R., Omar F., Rabiul I., and Wei X., "Recent Progress in Electrical Generators for Oceanic Wave Energy Conversion”, Digital Object Identifier 10.1109/ACCESS.2020.3012662, Aug.7, 2020.

4. Omar F., Koushik A., Abdirazak D., Mohamud M., and Rabiul I., "Electrical Power Generation from the Oceanic Wave for Sustainable Advancement in Renewable Energy Technologies", doi:10.3390/su12062178 www.mdpi.com/journal/sustainability, March 2020.

5. Farrok O., Islam M., and Sheikh M., "Analysis of the Oceanic Wave Dynamics for Generation of Electrical Energy Using a Linear Generator," J. of Energy, vol. 2016, pp. 3437027-1-3437027-14, 2016.

6. Vidura A., Nurjaya W., Iqbal M., Jaya I., "Ocean wave measurement and wave energy calculation using overtopping power plant scheme", : https://www.researchgate.net/publication/338870682, IOP Conference Series Earth and Environmental Science, January 2020.

7. Ralston K., Jiang H., Farrar T., "Waves in the Red Sea: response to monsoonal and mountain gap winds", Cont. Shelf Res. 65, 1e13, 2013.

8. Misaa A., Tayeb B., and Sabique L., "Wave Energy Converters: Barriers and Drivers", Proc. of the Int. Conf. on Industrial Engineering and Operations Management Dubai, UAE, March 10-12, 2020.

9. Simon P., "Introduction to Ocean Renewable Energy", Reference Module in Earth Systems and Environmental Sciences, file://C:/Users/ashassan/Desktop/Wave\%20Power\%20-\%20an\%20overview\% 20_\%20ScienceDirect\%20Topics.html, 2021.

10. Mohammed A. Al Yousif, "Renewable Energy Challenges and Opportunities in the Kingdom of Saudi Arabia", Saudi Arabian Monetary Authority, Sep. 2019.

11. Miguel E., Alexandros G., and Christopher N., "Recent Developments in Ocean Energy and Offshore Wind: Financial Challenges and Environmental Misconceptions", www.researchgate.net/publication/311996999, Sep. 2017.

12. Assessing the Global Wave Energy Potential, Paper no. OMAE2010-20473, ASME $201029^{\text {th }}$, International Conf. on Ocean, Offshore and Arctic Engineering, vol. 3, pp. 447-454, Shanghai, China, June 6-11, 2010.

13. Mohamad A., Rina S., Muhammad M., and Hardy A., "Wave Energy Convertors: A Review of the Technology and Power Generation", Int. Conf. on Math., Eng. and Industrial Applications, 2016.

14. Hongtao G., "Establishment of Motion Model for Wave Capture Buoy and Research on Hydrodynamic Performance of Floating-Type Wave Energy Converter", Polish Maritime Research Special Issue, S1 (86), Vol. 22; pp. 106-111, 10.1515-0041, 2015.

15. Joanna S., Victor A., Breivik Y., Jean-Raymond B., and Kristian M., "Effects of wave-induced forcing on a circulation model of the North Sea”, Ocean Dynamics, Springer-Verlag Berlin Heidelberg, Oct. 2016. 
16. Alawaji S., "Wind energy resource assessment in Saudi Arabia", part I; network design and description, Renewable Energy Int. J. (4), 19e28,1996.

17. Rehmana S., Halawani T. O., Mohandes M., "Wind power cost assessment at twenty locations in the KSA, Renewable Energy, 28: pp. 573, 2003.

18. David K. Ralston N., Houshuo J., and Thomas F., "Waves in the Red Sea: Response to monsoonal and mountain gap winds", https://doi.org/10.1016/j.csr.2013.05.017, Elsevier, Cont. Shelf Res. 65, 1-13, 2013.

19. Thorburn K., "Electric Energy Conversion Systems: Wave Energy and Hydropower", Doctoral thesis, Uppsala University, Sweden, 2006.

20. Drew B., Plummer A., and Sahinkaya M., "A review of wave energy converter technology", J. Power Energy Proc. Inst. Mech. Eng. A., 223, pp. 887- 902, 2009.

21. Tolman L., Balasubramaniyan B., Burroughs D., Chalikov V., Chao Y., Chen S., and Gerald M., "Development and implementation of wind generated ocean surface wave models at NCEP", Weather Forecast. 17, 311e333, 2002.

22. Rehman S., Ahmad A., "Assessment of wind energy potential for coastal locations of the kingdom of Saudi Arabia", Energy; 29, pp.1105e15, 2004.

23. Komen J., Cavaleri L., Donelan M., Hasselmann K., Hasselmann S., and. Janssen M, "Dynamics and Modelling of Ocean Waves", Cambridge University Press, Cambridge, 532 pp, 1994.

24. El-Morsy H., Ismail M., and Sherif A., "Generating The Electrical Energy from Sea Waves", J. of Soil Sciences and Agricultural Engineering, Mansoura Univ., Vol 10 (12):805-813, 2019.

25. Soerensen H., and Naef S., "Report on Technical Specification of Reference Technologies (wave and tidal power plant)", NEEDS Project Report 2008.

26. Witt M., Sheehan E., Bearhop S., and Godley B., "Assessing wave energy effects on biodiversity: The Wave Hub experience", Philos. Trans. of the Royal Society A: Math., Phys. and Eng. Sci., 370: 502-529, 2012.

27. Arshit A., Jay D., Mehul K., Shahnawaz A., and Zaid A., "Generation of Electricity from Ocean Waves", Int. Res. J. of Eng. and Tech. (IRJET) e-ISSN: 2395 -0056 Vol. 03 Issue: 04, Apr-2016.

28. Al-Abbadi N., "Wind energy resource assessment for five locations in Saudi Arabia", Renewable Energy, 30:1489e99, 2005.

29. Sahin A., Saudi A., "Wind power energy potential at the Northeastern region of Saudi Arabia", Renewable Energy;14(1e4):435e40, 1998.

30. Rehmana S., Al-Abbadib N., "Wind power characteristics on the North West Coast of Saudi Arabia", Energy \& Environment, 20(8), Vol. 21, No. 1, 2009.

31. Aboobacker M., Shanas R., Alsaafani A., Alaa M., and Albarakati A., "Wave energy resource assessment for the Red Sea", Elsevier, Renewable Energy xxx, 1e13, 2016.

32. Huang L., Liu J., Yu H., Qu R., Chen H., and Fang H., "Winding configuration and performance investigations of a tubular superconducting flux-switching linear generator," IEEE Tran. on App. Superconductivity, Vol. 25, no. 3, 2015.

33. Zhen L., Cui Y., Zhao H., Shi H., and Hyun S., "Effects of damping plate and taut line system on mooring stability of small wave energy converter", Math. Problems in Eng., Article ID 814095, Vol. 2015, 2015.

34. Tolman L., "User Manual and System Documentation of WAVEWATCH III", Version 4.18, p. 151, http://dx.doi.org/10.3390/ijerph2006030011. NOAA/NWS/NCEP/MMAB Tech. Note, 2014.

35. Rafael W., "Energy from Ocean Waves, Full Scale Experimental Verification of a Wave Energy Converter", Acta Un. Upsaliensis Uppsala, ISSN 1651-6214 ISBN 978-91-554-7354-9, 2008.

36. Kamranzad B., Etemad-Shahidi A., Chegini V., "Assessment of energy variation in the Persian Gulf”, Ocean. Eng. 70, 72e80, 2013.

37. Robertson, B., “Wave Energy: Resources and Technologies”, Reference Module in Earth Systems and Environmental Sciences, 2021.

38. Thomas T., and Dwarakish S., "Numerical Wave Modelling - A Review", Int. Conference on Water Resources, Coastal and Ocean Eng., ICWRCOE, doi: 10.1016/j.aqpro.2015.02.059 2015. 
39. Langodan S., Cavaleri L., Viswanadhapalli Y., and Hoteit I., "The Red Sea: a natural laboratory for wind and wave modeling", J. Phys. Oceanogr. 44, 3139e3159, 2014.

40. Behrang C., Shiva S., and Almerindo F., "Wave Energy Systems: An Overview of Different Wave Energy Converters and Recommendation for Future Improvements", Conference Paper, https://www.researchgate.net/publication/264490545, March 2014.

41. Rafael W., Jens E., and Mats L., "Wave climate off the Swedish west coast", Renewable Energy 34, 1600606, Ocean\%20and\%20Sea\%20Waves/WaveClimateofftheSwdishWestCoastRenewEng342009.pdf 2009.

42. Jean B., and Saleh Ab., "A revised formulation of ocean wave dissipation and its model impact", Technical Memorandum No. 509, Revised wave model dissipation, http://www.ecmwf.int/publications, Jan., 2007.

43. Mendes L., "Analysis of the Impact of a Pilot Zone for Wave Energy Conversion Offshore Portugal", Proc. of the 18th Int. Offshore and Polar Engineering Conf., Vancouver, BC, Canada, July 6-11, 2008.

44. Setoguchi T., Raghunathan, S., and Kaneko K., "Airturbine with self-pitch-controlled blades for wave energy conversion (estimation of performances in periodically oscillating flow)", Int. J. of Rotating Machinery, Vol. 3, no. 4, pp. 233-238, 1997.

45. Said S., El-Amin I., and Al - Shehri A., "Renewable energy potentials in Saudi Arabia. In Beirut regional collaboration workshop on energy efficiency and renewable energy technology", American Un. of Beirut, p. 76e82, April 2004.

46. Rehman S., Al-Abbadi N., "Wind shear coefficient, "turbulence intensity and wind power potential assessment for Dhulom", Saudi Arabia, Renewable Energy, 33:2653e60, 2008.

47. Rehman S., El-Amin I., Ahmad F., Shaahi S., Al-Shehri A., Bakhashwain J., "Wind power resource assessment for Rafha, Saudi Arabia", Renewable and Sustainable Energy Reviews, 937e50, 2007.

48. Elhadidy M., Shaahid S., "Wind resource assessment of Eastern Coastal region of Saudi Arabia", Desalination, 209:199e208, 2007.

49. EL-Tamaly H., Hamada M, Eltamaly A., "Computer simulation of wind energy system and applications", Proc. Int. Conf. in system analysis, control \& Design July 3e5; vol. 4. p. 84e93. Brno, Czech Republic, 1995.

50. Sun F., "Research of oscillating buoy wave energy device", Shanghai: Shanghai University, pp. 31, 2007.

51. Wang N., Li L., and Wang J., "Study on the Assessment of Performance of the Wave Energy Conversion Systems", Ocean Technology, Vol. 31, no. 4, pp. 75-78, 2012.

52. Gao T., Guan F., and Zhou L., "Experimental test on a kind of floating-type wave energy converter", ACTA ENERGIAE SOLARIS SINICA, Vol. 34, no. 1, pp. 177- 180, 2013.

53. Ruellan M., Ben Ahmed H., and Multon B., etc., "Design Methodology for a SEAREV Wave Energy Converter, IEEE Transactions on Energy Conversion, Vol. 25, no. 3, pp. 760-767, 2010. 